University of Nebraska - Lincoln

DigitalCommons@University of Nebraska - Lincoln

PreColumbian Textile Conference VIII /

Jornadas de Textiles PreColombinos VIII (2019)

Centre for Textile Research

$6-2020$

\title{
La Momia de Marburg: su recontextualización a través del ajuar y ofrenda textil
}

Isabel Martínez Armijo

Anna-Maria Begerock

Mercedes González

Follow this and additional works at: https://digitalcommons.unl.edu/pctviii

Part of the Art and Materials Conservation Commons, Fiber, Textile, and Weaving Arts Commons, Indigenous Studies Commons, Latin American Languages and Societies Commons, Museum Studies Commons, and the Other History of Art, Architecture, and Archaeology Commons

This Article is brought to you for free and open access by the Centre for Textile Research at DigitalCommons@University of Nebraska - Lincoln. It has been accepted for inclusion in PreColumbian Textile Conference VIII / Jornadas de Textiles PreColombinos VIII (2019) by an authorized administrator of DigitalCommons@University of Nebraska - Lincoln. 


\title{
La Momia de Marburg: su recontextualización a través del ajuar y ofrenda textil
}

\author{
Isabel Martínez Armijo \\ Anna-Maria Begerock \\ Mercedes González
}

Isabel Martínez Armijo Responsable del Departamento de Análisis de Textil Arqueológico - Instituto de Estudios Científicos en Momias-IECIM- C/Cetrería, 24-28232 Las Rozas-Madrid, España (imartinez.iecim@gmail.com, Isabel Martínez Armijo) Dra. Anna-Maria Begerock Responsable del Departamento de Arqueología Andina -IECIM (abegerock.iecim@gmail.com) Mercedes González Presidenta del Instituto de Estudios Científicos en Momias -IECIM (mgonzalez.iecim@gmail.com)

\begin{abstract}
Resumen
El análisis textil es un aporte fundamental para la recontextualización de individuos momificados y dentro de este contexto un caso interesante es el de la momia exhibida en el Museo del Instituto de Anatomía de la Universidad de Philipps, Marburg, Alemania. Este individuo, de sexo masculino, confirmado por la tomografía computarizada realizada en el año 2018, y acompañado de un ajuar textil y diversas ofrendas, se encuentra en relativas buenas condiciones de conservación y, de acuerdo a la escasa información disponible, habría ingresado a dicha institución alrededor de 1892-1893 procedente de la ciudad de Arica.

En este trabajo se presentan los resultados del análisis de los textiles que forman parte del ajuar y la ofrenda asociadas a dicha momia, los cuales presentan la característica composición espacial, técnica de confección, materia prima, colores e iconografía de los tejidos de la cultura Arica (ca. 1000-1470 d.C.) que se desarrolló en la costa y valles de Arica en el norte de Chile en el período Intermedio tardío. La importancia de este estudio recae en que estos tejidos permitieron recontextualizar el conjunto a la sociedad de la cual formó parte y dar luces sobre el status o rol que pudo tener este individuo en vida.
\end{abstract}

Palabras claves: Cultura Arica, momias, ajuar funerario, ofrendas, recontextualización

\begin{abstract}
Textile analysis is a fundamental contribution to the recontextualization of mummified individuals. Within this context, the mummy exhibited in the Museum of the Institute of Anatomy of the University of Philipps, Marburg, Germany presents an interesting case. This male individual, confirmed by the CT scan made in 2018, received textile grave goods and various other offerings - all in good condition. According to the limited information available, the mummy and funerary goods are from Arica and entered the institution's collection around 1892-1893.

This paper presents the results of the analysis of the textiles that are part of the grave goods associated with this mummy. They present the characteristic spatial composition, manufacturing technique, raw material, colours and iconography of the Arica culture textiles that developed on the coast and valleys of Arica in northern Chile in the Late Intermediate Period (ca. 1000-1470 AD). The importance of this study lies in the fact that these textiles allowed a recontextualizing of the individual into the society to which it was a part and shedding light on the status or role that this individual could have in life.
\end{abstract}

Keywords: Arica Culture, Mummies, Grave Goods, Offerings, Recontextualization

DOI: $10.32873 /$ unl.dc.zea.1208

Published in PreColumbian Textile Conference VIII / Jornadas de Textiles PreColombinos VIII, ed. Lena Bjerregaard and Ann Peters (Lincoln, NE: Zea Books, 2020). https://digitalcommons.unl.edu/zeabook/ 


\section{Résumé}

L'analyse textile est une contribution fondamentale pour la recontextualisation des individus momifiés. Dans ce contexte, la momie conservée au Musée de l'Institut d'Anatomie de l'Université de Philips, Marburg, en Allemagne présente un cas intéressant. Cet individu de sexe masculin, confirmé par un CT scan réalisé en 2018, et accompagné de textiles et de diverses offrandes, a été découvert dans un état de conservation relativement bon. Selon le peu d'information disponible, la momie et ses offrandes proviennent d'Arica et sont entrées dans la collection de l'institut autour de 1892-1893.

Cet article présente les résultats de l'analyse des textiles qui composent le mobilier associé à la momie, lesquels présentent une composition spatiale caractéristique, une technique d'élaboration, des matières premières, des couleurs et une iconographie des tissus propre de la culture Arica (ca. 1000-1470). L'importance de cette étude repose sur ces tissus qui ont permis de recontextualiser l'ensemble, soit à la société à laquelle il appartenait soit d'éclairer le statut ou le rôle que cet individu aurait pu avoir durant sa vie.

Mots-clés: Culture Arica, momies, trousseau textile, offrandes, recontextualisation

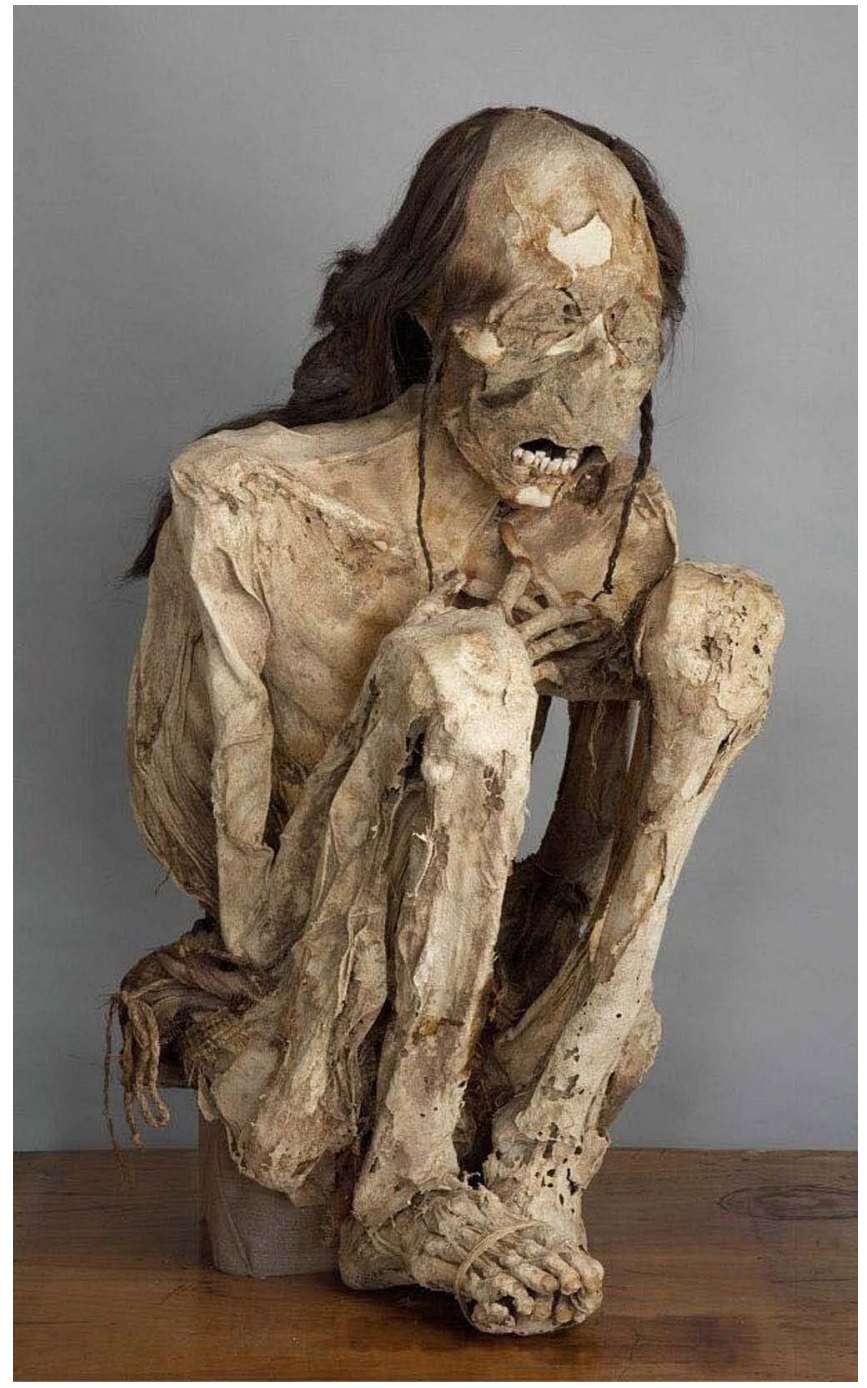

Figura 1. Vista frontal de la momia de Marburg (Fotografía AnnaMaria Begerock, 2016-2018).

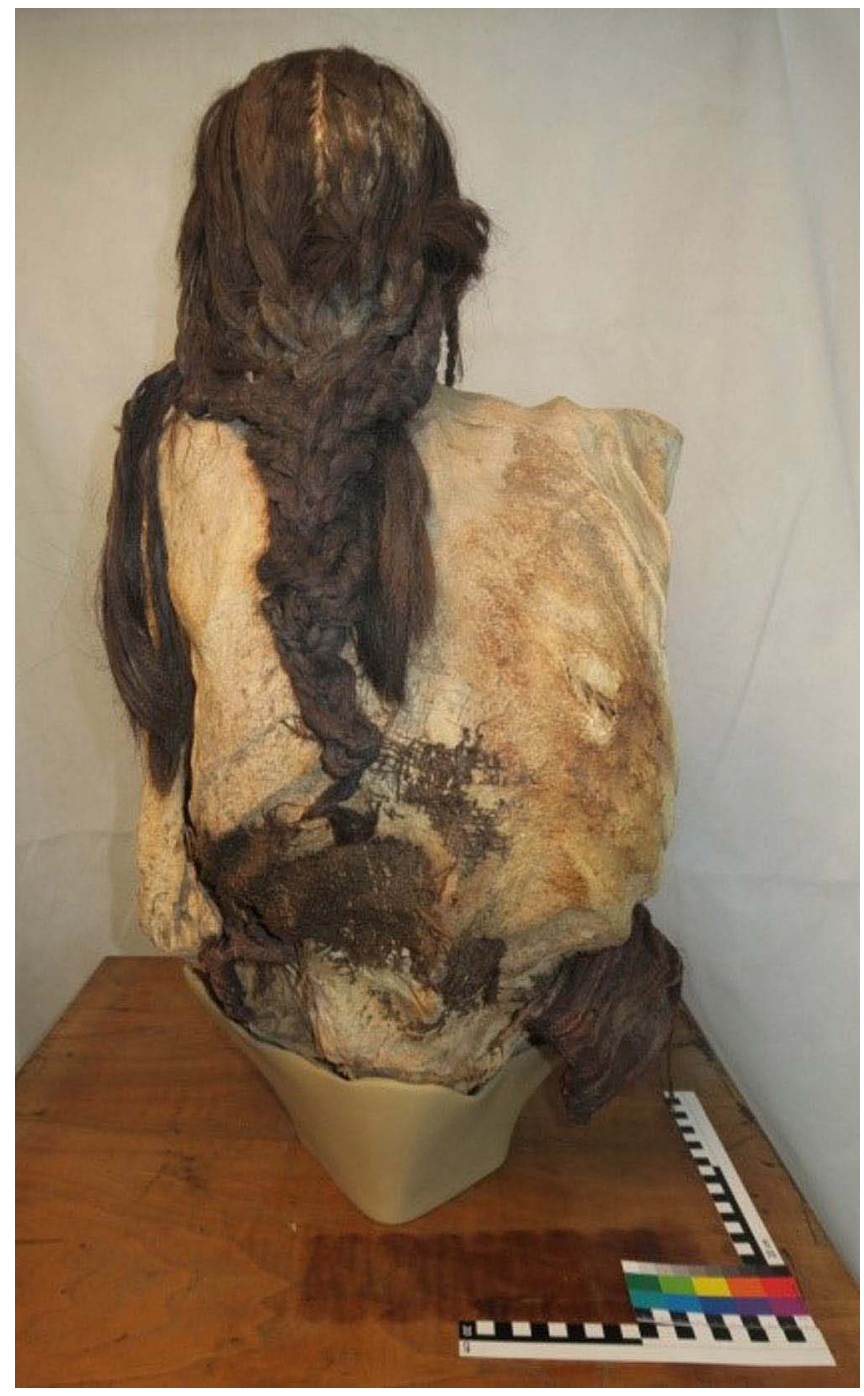

Figura 2. Vista posterior de la momia de Marburg (Fotografía Anna-Maria Begerock, 2016-2018). 
En el presente trabajo se expone parte de los resultados del análisis de los textiles del ajuar de la momia de Marburg, que pertenece a la colección del Museum Anatomicum de la Philipps Universität, Marburg, Alemania y que habría ingresado a dicha institución alrededor de 1892-1893, como regalo del fisiólogo Rudolph Eduard Külz, quien trabajaba en la Universidad de Marburg. En aquella ocasión fue presentada como una momia femenina -por su larga cabellera y su peinado de múltiples trenzas- procedente de la ciudad de Arica, con una gran cantidad de ofrendas asociadas. En el año 2016 la arqueóloga Dra. Anna-Maria Begerock tuvo la oportunidad de analizarla, constatando que corresponde a un individuo masculino(1), encontrándose en su conjunto en relativas buenas condiciones de conservación. Se halla en una posición sentada con las piernas fuertemente flexionadas hacia el pecho, con el pie derecho sobre el izquierdo, así como la mano derecha sobre la izquierda apoyadas en la parte alta del tórax (Figuras 1 y 2). Forman parte de la ofrenda, una serie de objetos de madera característicos de la ergología marítima de las poblaciones que habitaron la costa norte de Chile y sur del Perú durante el período Intermedio tardío, tales como cabezales de arpón, un capacho en miniatura y restos de una posible balsa de tres palos con franjas paralelas realizadas con pigmento rojo, así como cerámica no decorada y cuatro textiles completos, entre otros (Figuras 3 y 4). Directamente asociados al cuerpo se hallan los textiles que forman el ajuar.

Por los antecedentes a disposición respecto a la procedencia del conjunto funerario, así como por sus características generales, fue posible adscribirlo preliminarmente al período Intermedio tardío (ca. 100o-1470 d.C.) de la zona de Arica, extremo norte de Chile.

Siendo un conjunto funerario descontextualizado, el análisis de los componentes de su ajuar y ofrenda son de fundamental apoyo para su recontextualización. La iconografía plasmada en los textiles nos entrega valiosa información para determinar la filiación cultural a la cual pertenecieron, circunscribir temporal y geográficamente el contexto y más específicamente permite acercarnos a la cosmovisión de las poblaciones que los crearon y usaron.

\section{Textiles del Ajuar}

Las piezas textiles presentan de un regular a mal estado de conservación. Sin embargo, fue posible identificar el tipo de textil por la técnica, la forma, las terminaciones y la
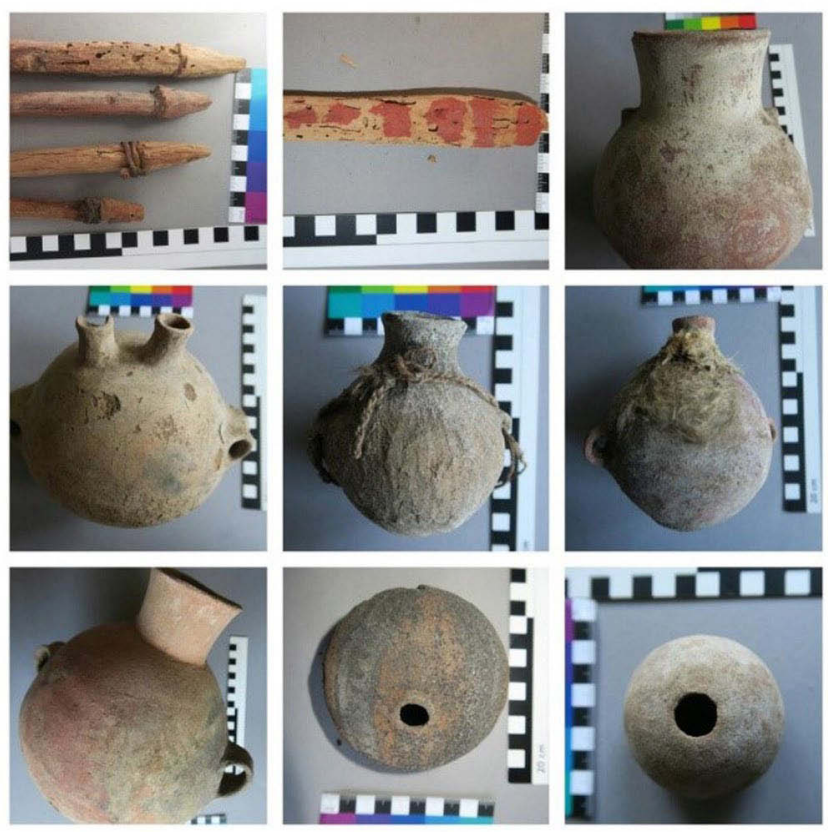

Figura 3. Parte de los objetos suntuarios que forman la ofrenda (Fotografías Anna-Maria Begerock e Isabel Martínez A., 2018).
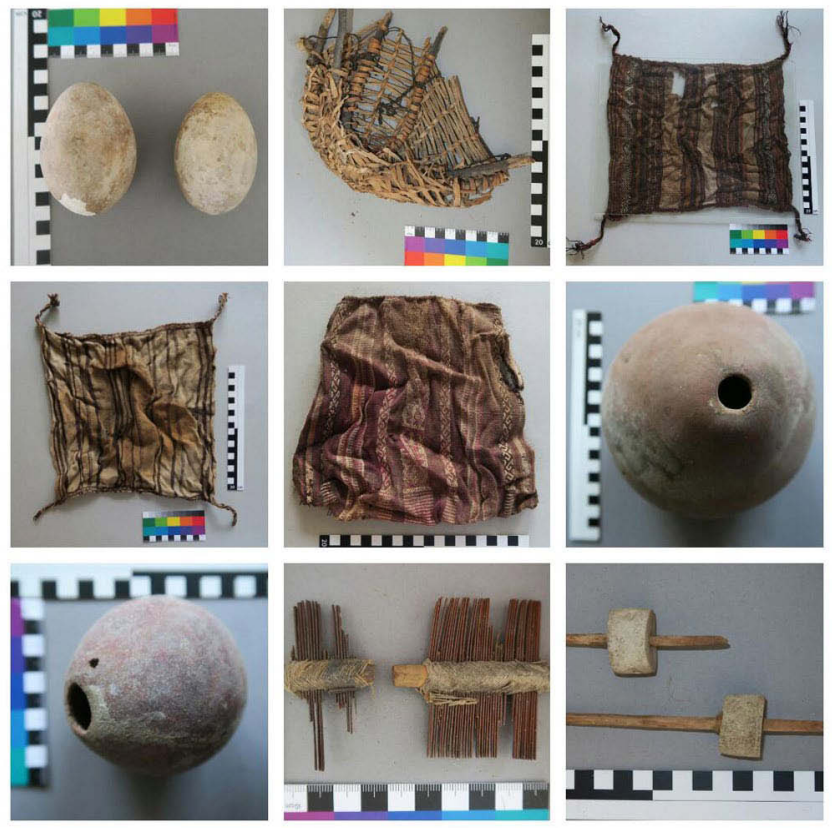

Figura 4. Parte de los objetos suntuarios que forman la ofrenda (Fotografías Anna-Maria Begerock e Isabel Martínez A., 2018).

1. Lo corroboran también el peinado, que corresponde al tipo $3 \cdot 3$ de la

clasificación de peinados precolombinos realizada por Bernardo Arriaza y colaboradores (1986:357), que se asocia a individuos masculinos del periodo Intermedio Tardío de la zona de Arica, y la tomografía axial computarizada realizada el 5 de junio de 2018 en la Universitätsklinikum, Marburg, Alemania. 

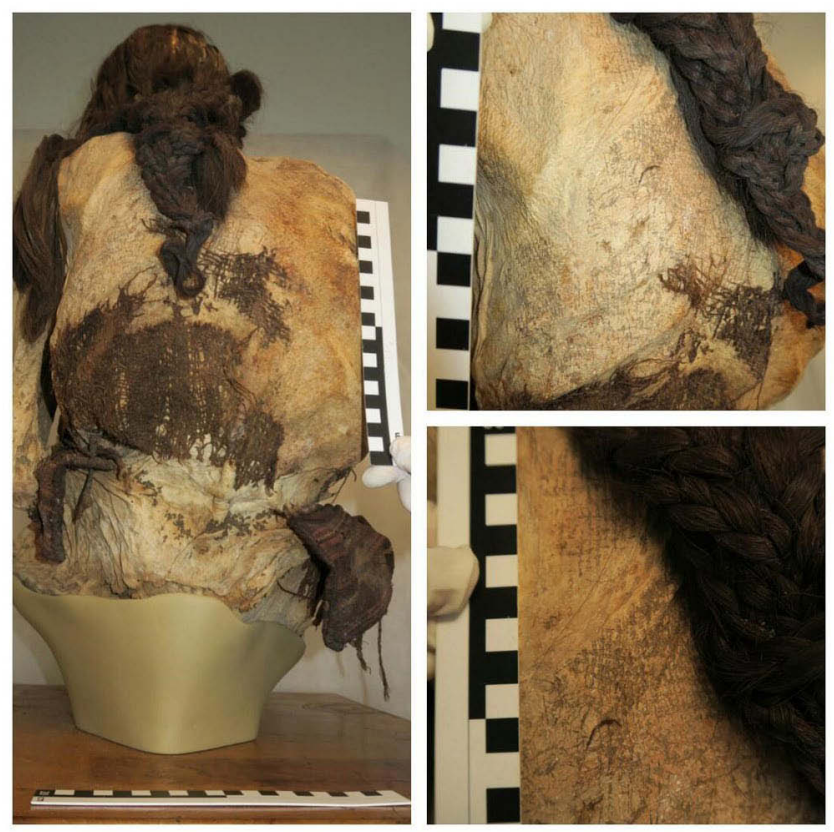

Figura 5. Vista de los restos e improntas en la piel de un unku que cubría el cuerpo del individuo (Fotografías Isabel Martínez A., 2018).

composición espacial. Todos estos tejidos fueron hechos con pelo de camélido y en el caso de la prenda con motivos, los apéndices son en fibra de algodón.

En la zona de la espalda se identificaron los restos de un unku de color natural café oscuro con franjas y/o listas en color crema, que cubría casi todo el cuerpo, que además dejó marcadas improntas en la piel (Figura 5). Esta pieza fue confeccionada con la técnica de tejido llano $2 \times 2$.

En la rodilla derecha y dorso de las manos, así como en ciertas zonas de las piernas, se observan los restos de otro textil, probablemente un segundo unku, de color café oscuro con listas y franjas en color crema, de factura más fina y realizado con la técnica de faz de urdimbre, que habría recubierto el cuerpo (Figura 6).

Ceñido a la cintura, in situ, se observa un textil de forma rectangular que, por su ubicación y posición en relación al cuerpo del individuo, su forma, terminaciones laterales, composición espacial y técnica de manufactura, corresponde a una bolsa-faja (Figura 7). Este tipo de textil, junto con la chuspa, era un complemento de la vestimenta y consistía en "una pieza rectangular, doblada por la mitad, cosida en tres de sus cuatro costados, aunque dejando en el centro del borde superior una abertura, para facilitar su uso como bolsa, a la vez que faja" (Horta 1997:108, nota ${ }^{\circ} 20$ )
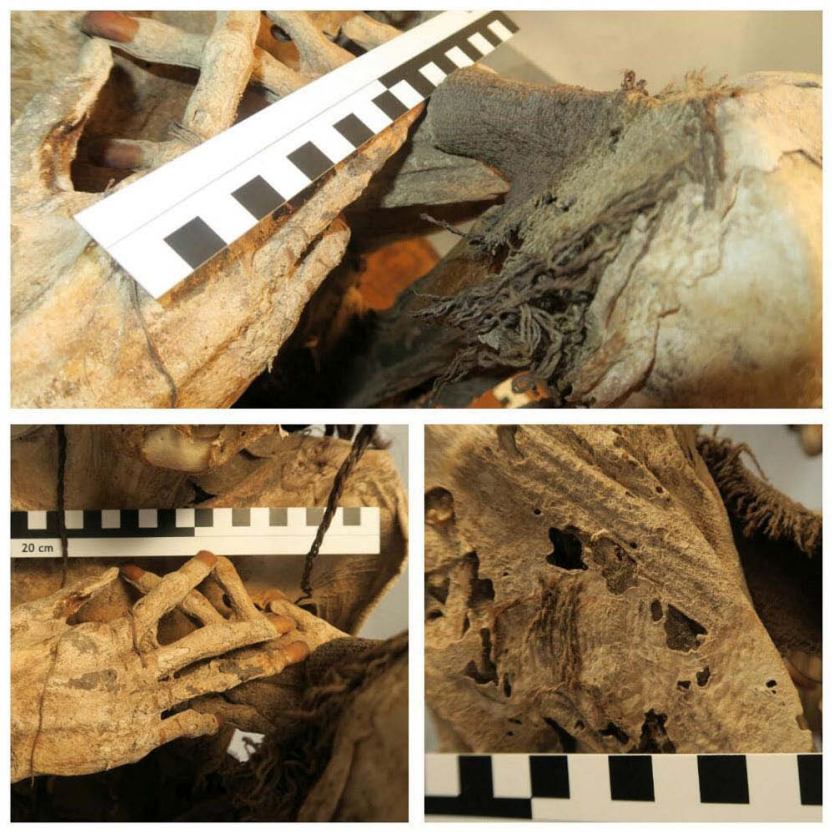

Figura 6. Vista de los restos de otro posible unku que cubría el cuerpo del individuo (Fotografías Isabel Martínez A., 2018).

con cordones que permitían su amarre alrededor de la cintura y en su interior se guardaban hojas de coca (Erythroxylum coca) y llipta(2).

La composición espacial de esta pieza consiste en una serie de franjas en el sentido más largo (horizontal), presentando ambas caras (externa e interna) un patrón distinto. La cara externa se divide en tres zonas o grupos con listas de diversos colores, café, café oscuro, crema y rojo, con diferentes anchos y estructuras, sobre una pampa monocroma de color café oscuro; mientras que la cara interna también es listada en el sentido horizontal de la pieza, pero a diferencia de la cara externa presenta solo dos combinaciones de colores que se alternan, café oscuro y café, con diferentes anchos (Figura 8). En el interior, hacia el borde lateral derecho, se observó una protuberancia indicando que contiene algún elemento y probablemente corresponda a hojas de coca.

El tercer textil que forma parte del ajuar se encontraba en la zona abdominal baja, también in situ, debajo de la bolsafaja, y presenta una rica y variada iconografía. Por su composición espacial, colores y terminaciones, realizadas con la técnica de torzal, es posible identificar esta pieza como una inkuña, la cual fue reutilizada para formar un taparrabo, evidenciado por los dos apéndices presentes en uno de sus

2. Es una masa hecha con una mezcla de cal y ceniza para potenciar la extracción del alcaloide de la hoja de coca. 

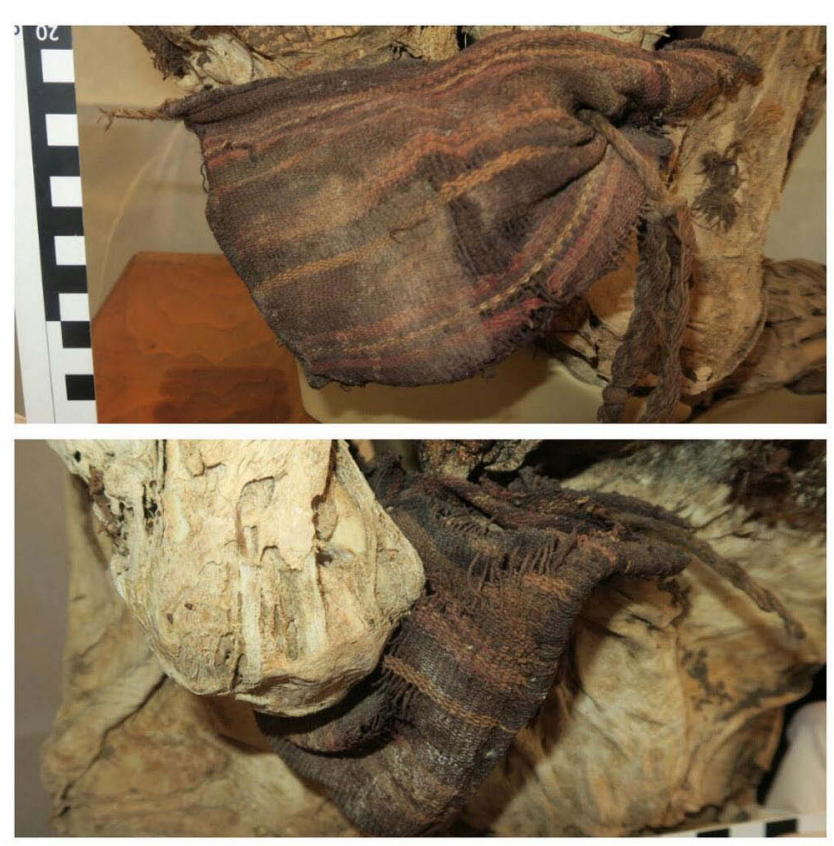

Figura 7. Vistas laterales derecha e izquierda, respectivamente, del cuerpo del individuo donde se aprecian los bordes laterales de la bolsa-faja aún ceñida a la cintura (Fotografías Isabel Martínez A., 2018).

bordes largos y por su ubicación en el cuerpo (Figura 9). Esta prenda, de forma cuadrangular o trapezoidal, se colocaba entre las piernas sujeta a la cadera mediante los cordones laterales. Según Horta (2005:17), no habría formado parte de la indumentaria de la cultura Arica por ser muy escaso y habría sido una manifestación foránea, sobre todo hacia finales del Intermedio tardío.

La inkuña (Quechua) o tari (Aymara) formaba parte de la indumentaria andina prehispánica del norte de Chile en el período Intermedio tardío y consiste en tejido:

"cuadrangular, cuyas dimensiones no superan los 45-6o cm. Las orillas de urdimbre presentan una terminación muy característica llamada 'trama en torzal' que se prolonga en las cuatro esquinas del textil, en forma de asas. En su gran mayoría son decoradas verticalmente con listas lisas de variados colores y franjas con diseños en la técnica de urdimbres complementarias" (Horta 2005:18)

Estas formaban un bulto amarrando sus cuatro esquinas, en cuyo interior se colocaban hojas de coca.

La decoración textil de esta pieza se da al interior de dos franjas verticales modulares, con una más ancha central, intercaladas por tres pares de listas monocromas en ocre, azul y

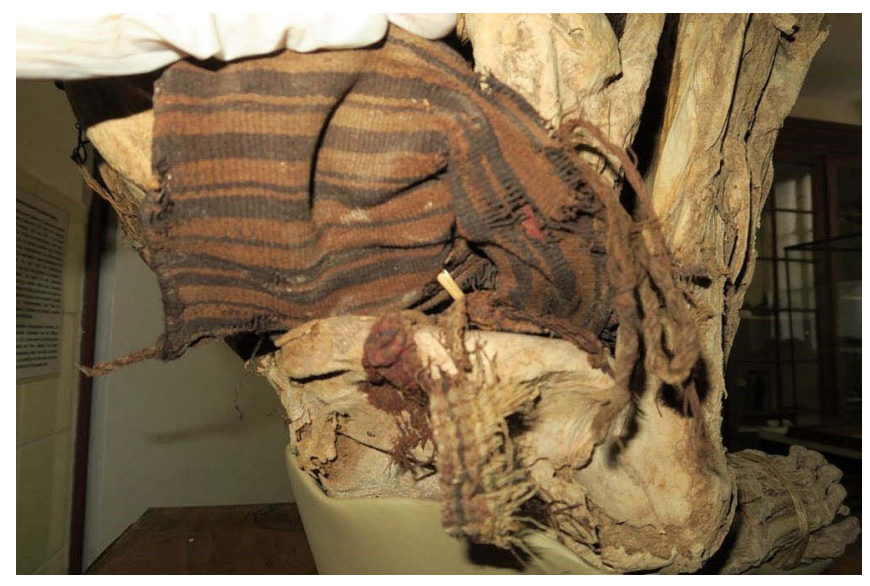

Figura 8. Vista de la cara interna listada de la bolsa-faja (Fotografía Anna-Maria Begerock, 2016).

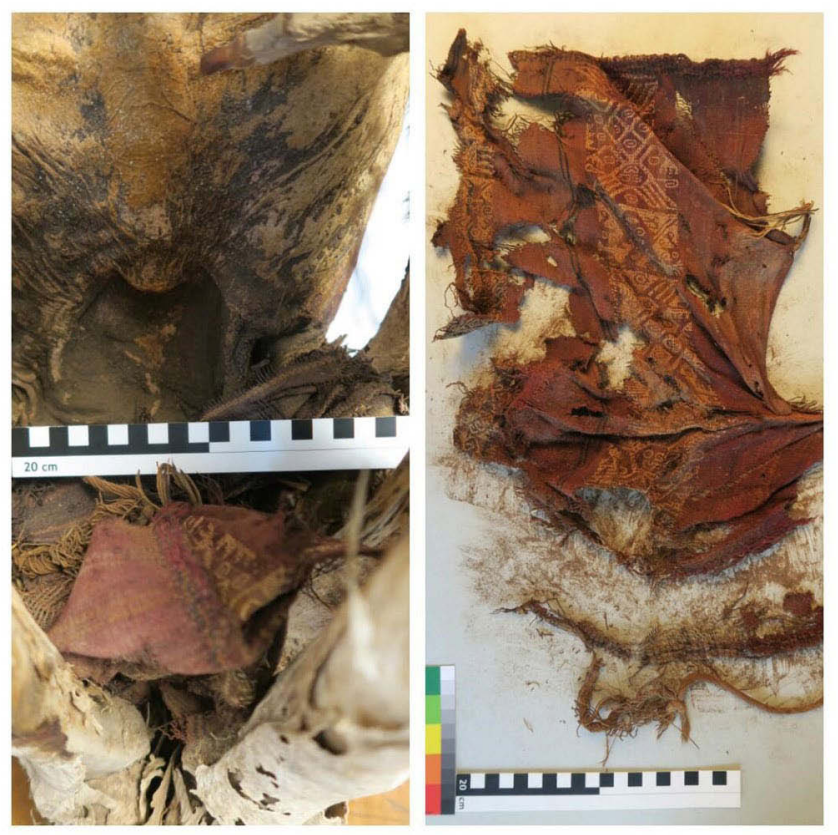

Figura 9. Vistas de la inkuña-taparrabo; derecha, in situ en las entrepiernas de la momia e izquierda, extendida (Fotografías Isabel Martínez A., 2018).

gris violáceo, sobre una pampa de color granate. En la franja central es posible observar cuatro módulos de diseño donde las figuras fueron realizadas en hilos de color crema sobre un fondo listado en morado oscuro/morado claro/ocre/morado oscuro/morado claro/morado oscuro/ocre/morado claro/morado oscuro, en su cara 'positiva' y de manera inversa en su cara 'negativa'. El motivo del primer y tercer módulo consiste en un ser antropomorfo rectilíneo bicéfalo con cuatro apéndices cefálicos que se prolongan hacia arriba de la cabeza en dirección diagonal, dos a cada lado de la cabeza, y dos líneas 


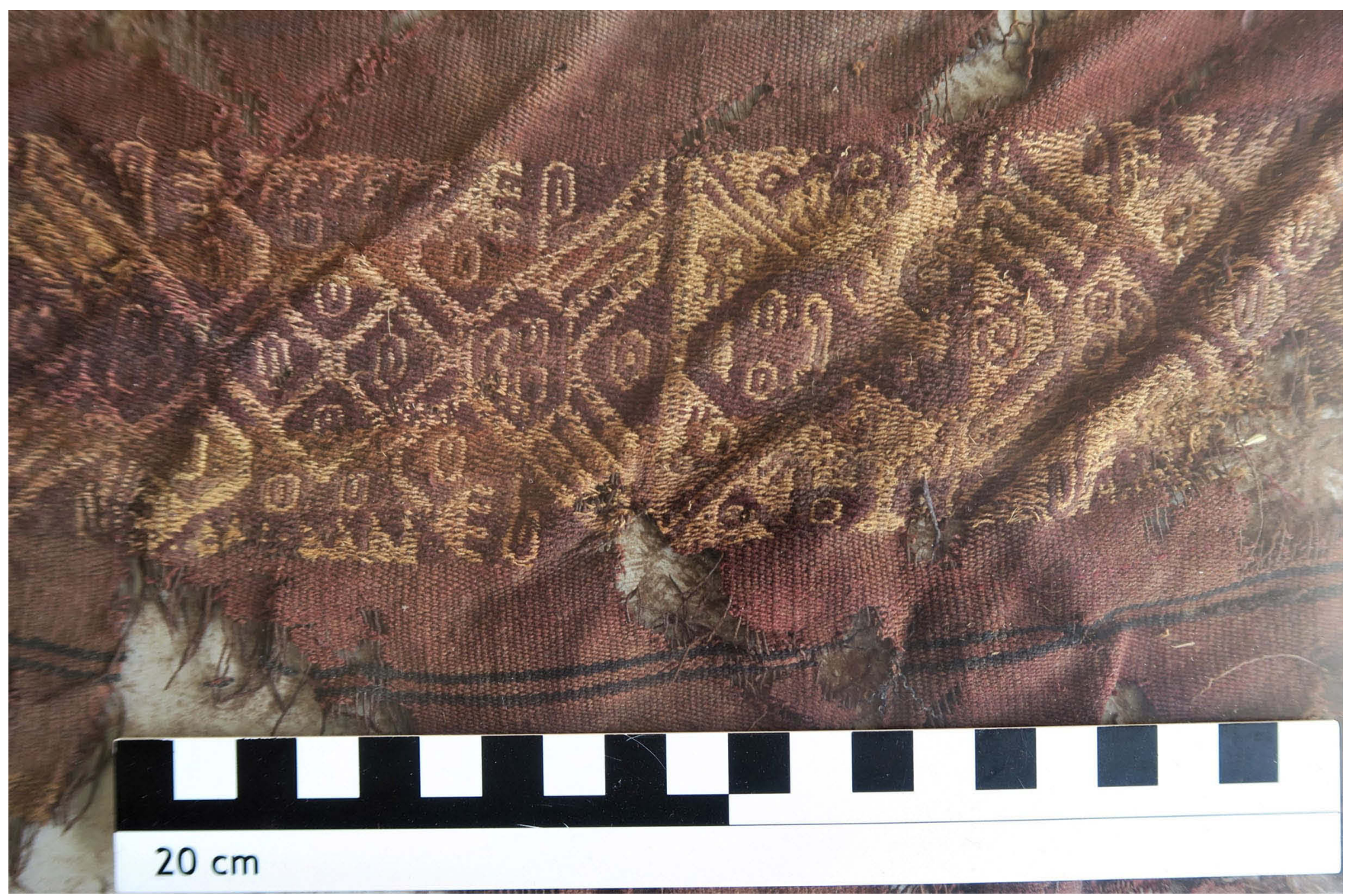

Figura 10. Ser antropomorfo bicéfalo del primer módulo de diseño, arriba y abajo (Fotografía Isabel Martínez A., 2018).

rectas laterales que parten de los apéndices externos y que terminan curvados en espiral hacia arriba. Presenta dos ojos y una boca 'sonriente', en cada una de las caras, y las cuatro extremidades superiores se encuentran flectadas en direcciones opuestas, terminando en una mano con cuatro dedos cada una. El cuerpo es de forma romboidal, cuatripartito con cuatro hexágonos concéntricos. Se observan elementos acompañantes alrededor de la figura que consisten en diez hexágonos concéntricos: uno sobre cada cabeza entre los apéndices cefálicos (total: 2); uno sobre cada una de las extremidades superiores (total: 4); dos a cada lado del cuerpo (total: 4) y dos motivos o bordes 'aserrados', uno a cada lado del cuerpo, en los extremos laterales de la franja (Figura 10). La figura del cuarto módulo corresponde a la mitad exacta de la figura apenas descrita.

En la clasificación de Helena Horta (2005) sobre la iconografía textil de la cultura Arica, esta figura pertenece al Grupo 1 de los antropomorfos, los cuales, "no presentan ni piernas ni pies, sino curiosas extremidades arqueadas que rematan en uno, dos o tres ganchos" (Horta 2005:30). En relación a los apéndices cefálicos, estos conformarían un tocado erguido de tipo radiado, el más común encontrado en las figuras antropomorfas y para los apéndices laterales que terminan en espiral, esta autora propone que pueden corresponder a orejeras.

En el segundo módulo el motivo principal se asemeja a una cara zoomorfa antropomorfizada, con dos ojos, una boca 'sonriente' y un triángulo truncado en la zona que correspondería a la frente; además de cuatro apéndices laterales finos, dos por cada lado, a nivel de los pómulos que se prolongan hacia arriba en dirección diagonal y otros dos, uno a cada lado, por debajo de los apéndices anteriormente mencionado. Presenta un largo cuello orientado diagonalmente con dos hexágonos concéntricos en su interior. En Horta (2005:60, 77 y 78; Figuras 141 y 144) se registra un motivo de similares características que corresponde a un felino humanizado. Esta figura en la pieza bajo análisis se halla rodeada por cuatro figuras zoomorfas: a) dos a cada lado de la cabeza por sobre los apéndices laterales que se presentan de perfil y especulares mirando hacia la cabeza de la figura dominante, que presentan cada uno un ojo, una boca alargada semejante al pico de un ave o a un hocico, y una especie de extremidad superior extendida hacia adelante rematada en ángulo recto hacia arriba; b) dos a cada 


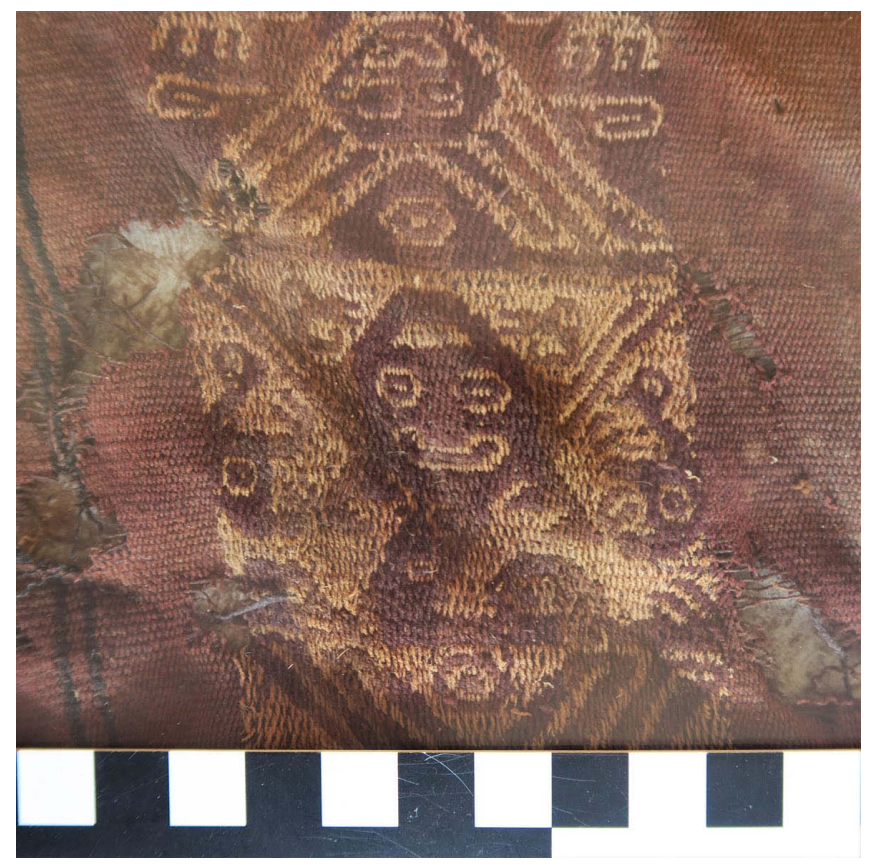

Figura 11. Cara de felino humanizado rodeada por seres zoomorfos no identificados (Fotografía Isabel Martínez A., 2018). lado de la figura dominante, pero por debajo de los apéndices faciales, en la misma posición y dirección de los anteriormente descritos, así como la misma forma de la cabeza, solo que estos presentan además un cuello largo y el cuerpo también de perfil y en posición aparentemente 'sentada', en cuyo interior se halla una especie de hexágono concéntrico, con cada uno dos extremidades, posiblemente superior e inferior, extendidas hacia adelante rematadas en dos especies de 'dedos' o ganchos en dirección al cuerpo (Figura 11). Estos cuatro acompañantes zoomorfos de perfil corresponderían a un animal no identificado por no poseer más rasgos distintivos y por su baja recurrencia (Horta 2005:65, 89 y 91, Figuras 190 y 205) y también se halla asociado a una figura del felino humanizado mencionado anteriormente en la clasificación de Helena Horta.

En la franja lateral se pueden apreciar seis módulos con motivos en hilos de color crema, que forman los motivos tanto en 'positivo' como en 'negativo', sobre un fondo listado en el siguiente orden: rojo/azul oscuro/ocre/rojo/azul oscuro/ocre/rojo (Figura 12).
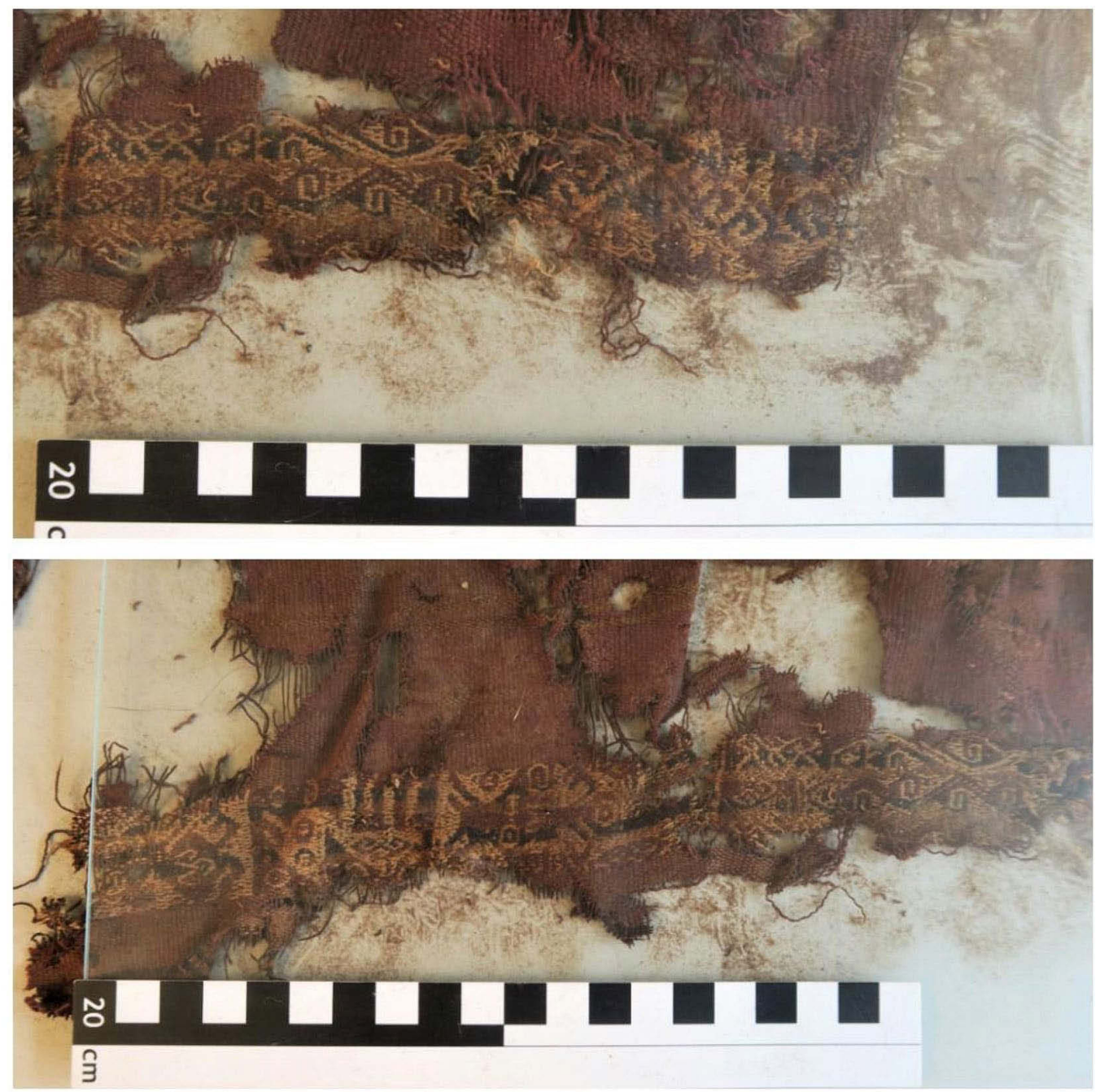

Figura 12. Franja lateral con seis módulos de diseño (Fotografía Isabel Martínez A., 2018). 

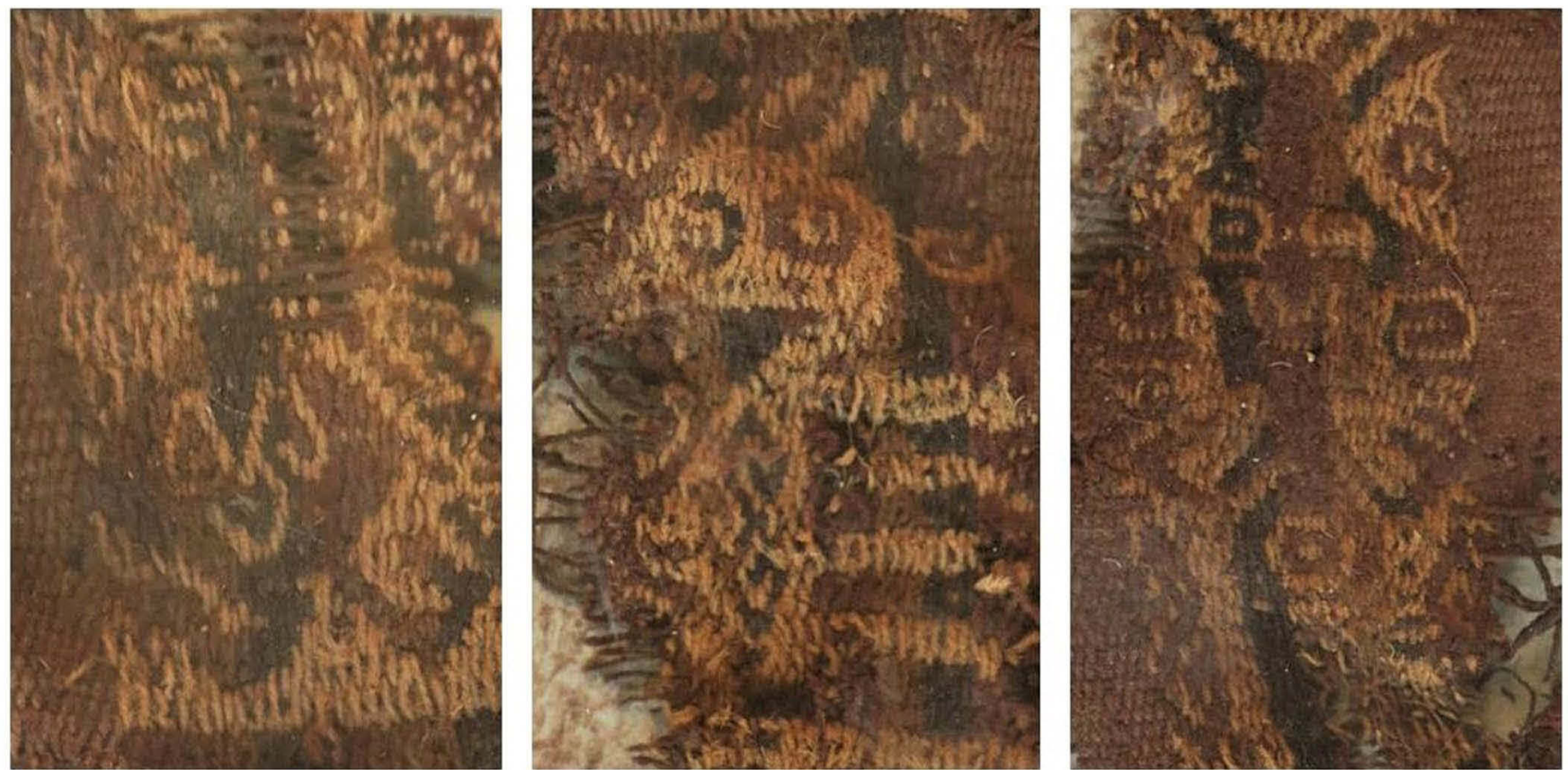

Figura 13. Motivos de los tres primeros módulos de la inkuña-taparrabo (Fotografías Isabel Martínez A., 2018).

El primer módulo contiene una figura antropomorfa erguida sobre pies de características muy similares a la Figura 58 del Grupo 3 la clasificación de Horta (2005:29 y 47). El siguiente módulo representa a un camélido de cuatro patas, de perfil (Horta 2005:63 y 86, Figura 180). El tercer módulo muestra una figura antropomorfa, erguida de frente, con un tocado de forma triangular en su base y en la clasificación de Horta (2005:44, Figura 48) existe un ícono muy similar donde la figura humana presenta tanto un "tocado erguido" como "orejeras", representadas por los ganchos (Figura 13).

El cuarto módulo contiene íconos no figurativos como "figuras geométricas independientes", específicamente "volutas 'S'” (Horta 2005:93, 96 y 107; Figuras 209 y 311) (Figura 14). El quinto módulo, también de íconos no figurativos, similares a ganchos terminados en puntas o triángulos. Se distribuyen en listas verticales, con ejes en forma de zig-zag desde los cuales emergen los ganchos. Estos motivos los encontramos en la clasificación de Horta (2005:93 y 102, Figuras 275 y 276) descritos como "íconos no-figurativos", "figuras geométricas independientes" y subcategoría "ganchos". Finalmente, el sexto, y último módulo, es otro ícono no figurativo que corresponde a una "franja diagonal aserrada" (Horta 2005:94 y 109, Figura 322), que entra en las "composiciones geométricas" (Figura 15).

La inkuña-taparrabo, apenas descrita, es un elemento importante para recontextualizar a la 'momia de Marburg', en cuanto nos permite, a través del estudio de su composición espacial e iconografía, acotar el fechado de su producción y utilización, como veremos en el siguiente apartado.

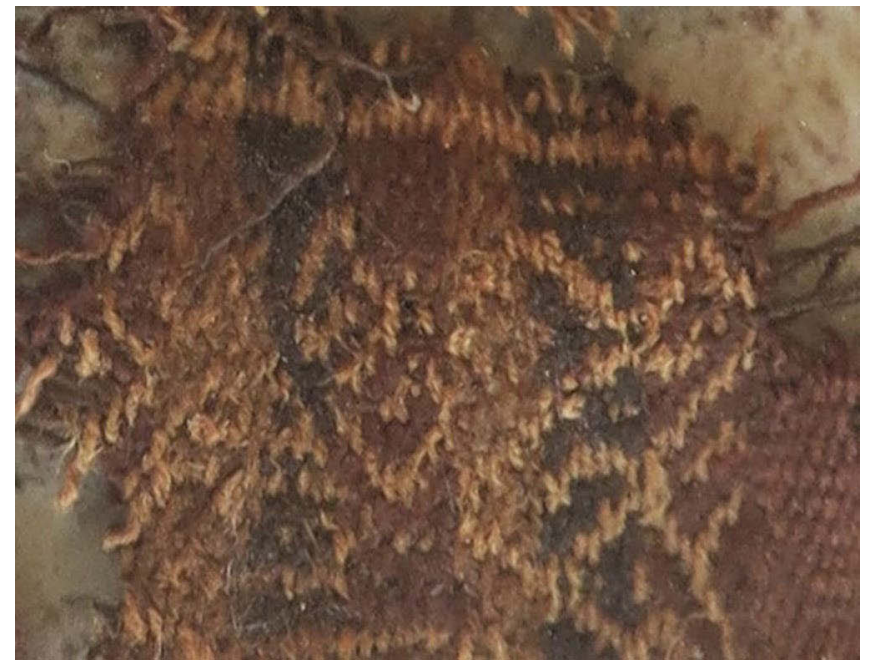

Figura 14. Íconos no figurativos del cuarto módulo (Fotografía Isabel Martínez A., 2018).

\section{Textiles de la Ofrenda}

Se compone de dos chuspas y dos inkuñas de fibra o pelo de camélido, en buen estado de conservación. La chuspa o ch'uspa formaba parte de la indumentaria andina y consiste en una bolsa sub-rectangular, cuadrada o trapezoidal, que generalmente se llevaba en bandolera, tejida en fibra de camélido, cuya función principal era la de guardar y transportar las hojas de coca (Erythroxylum coca) (Horta y Agüero 2000:48; Arriaza y Standen 2008:92). 

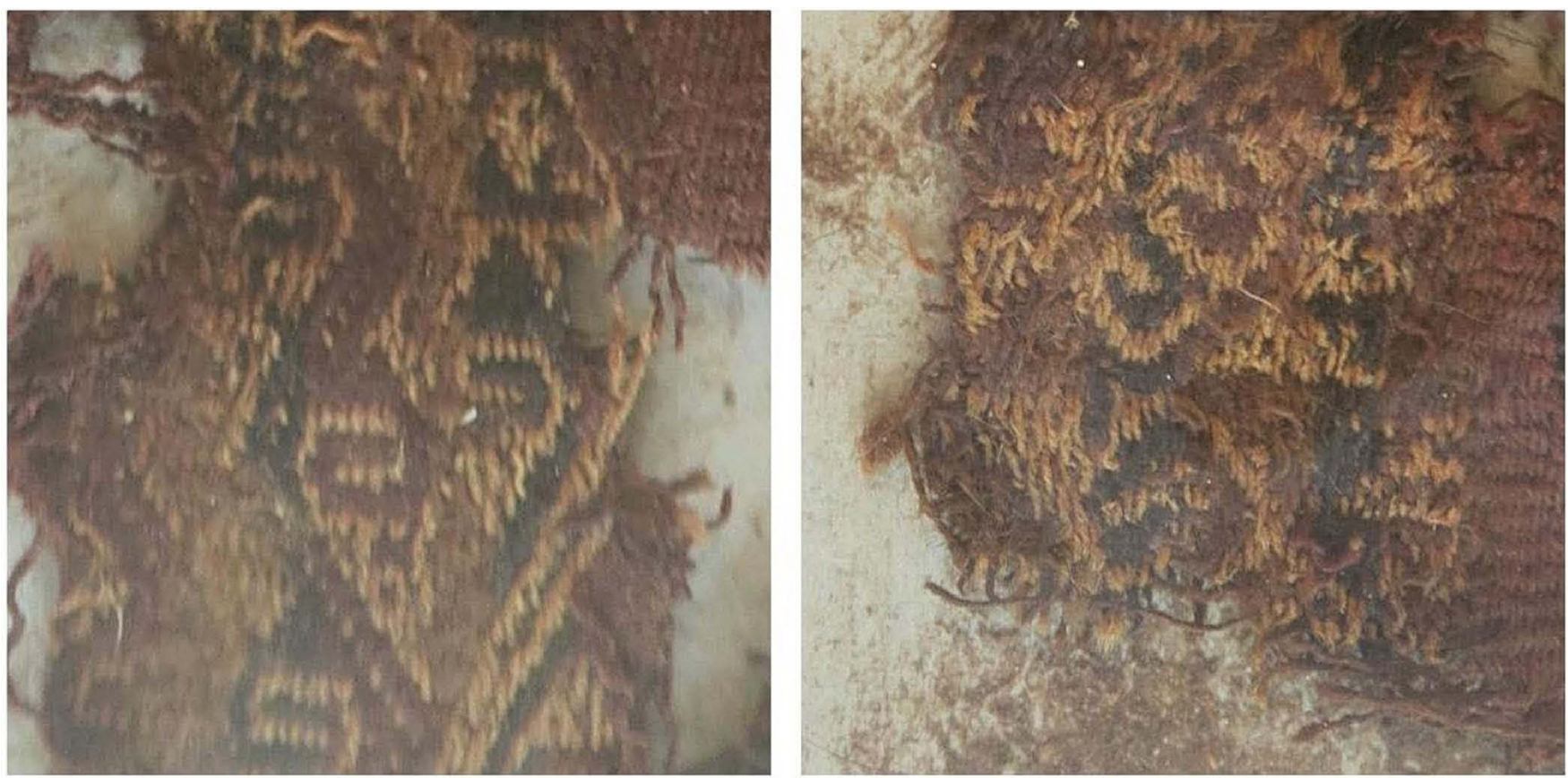

Figura 15. Izquierda, módulo con motivos no figurativos semejantes a ganchos dispuestos en hileras verticales; derecha, módulo con franja diagonal aserrada (Fotografías Isabel Martínez A., 2018).

La primera chuspa (Figura 16) presenta una disposición del cuerpo, tanto en su cara anterior como posterior, de tres franjas del mismo ancho, en el sentido vertical, que contienen íconos no figurativos similares a ganchos terminados en puntas o triángulos (cabeza triangular), que se distribuyen en listas verticales, con ejes en forma de zig-zag, desde los cuales emergen los ganchos de color crema sobre fondo color café oscuro, y rematan en un peinecillo largo o k'utu en color crema y café oscuro. En la clasificación de Helena Horta hay un motivo de similares características que está catalogado como "íconos no figurativos", categoría "figuras geométricas independientes" y subcategoría "ganchos" (Horta 2005:93 y 102, Figura 275). Estas franjas están intercaladas por cuatro bloques de listas monocromas de color verde-gris, verde y una más ancha central de color ocre sobre una pampa de color café oscuro. La distribución espacial en la cara anterior, de izquierda a derecha, es la siguiente, con cuatro bloques de listas monocromas café oscuro/verde-gris/café oscuro/verde/café oscuro/ocre/café oscuro/verde-gris/café oscuro/verde/café oscuro, intercalados por tres franjas con motivos en crema y café oscuro. En la cara posterior se invierte solamente la secuencia entre las listas verde-gris y verde.

El borde superior, o la boca, consiste en una primera, y última, pasada de trama de mayor grosor que en el resto del cuerpo y presenta un cordón de color rojo que se encuentra en parte cosido en ambos extremos de los bordes laterales superiores y con algunas puntadas a lo largo de la boca, terminando en una especie de mariposa que cuelga a lo largo de la pieza, encontrándose fijada por medio de una puntada en la base de la chuspa. Este cordón es característico de las chuspas de la cultura Arica y tiene como función la de cerrarla por boca (Horta 2005:17).

La cara anterior presenta una particularidad interesante y que puede ser diagnóstica para contextualizar temporal y geográficamente la pieza. Esta consiste en la presencia de dos pequeños bolsillos sobresalientes ubicados en la zona media de ambas franjas laterales con diseño, que fueron realizados durante el proceso del tejido de la chuspa.

La segunda chuspa (Figura 17) se halla con una deformación estructural y la composición espacial consiste en siete franjas verticales de diferentes anchos: una central modular con motivos figurativos; cuatro con íconos no-figurativos; y dos con peinecillo; con listas monocromas de diversos colores en los bordes laterales. La franja central, con hilos de urdimbre de color rojo y crema, se divide en tres módulos donde se repite el mismo motivo figurativo, que corresponde a un ser zoomorfo bicéfalo, con las cabezas dirigidas en orientaciones opuestas y con el cuerpo diagonal (Figura 18). En ambas cabezas, de forma hexagonal, se distinguen claramente un par de ojos y una especie de nariz larga en forma de clepsidra. Estas cabezas están unidas 


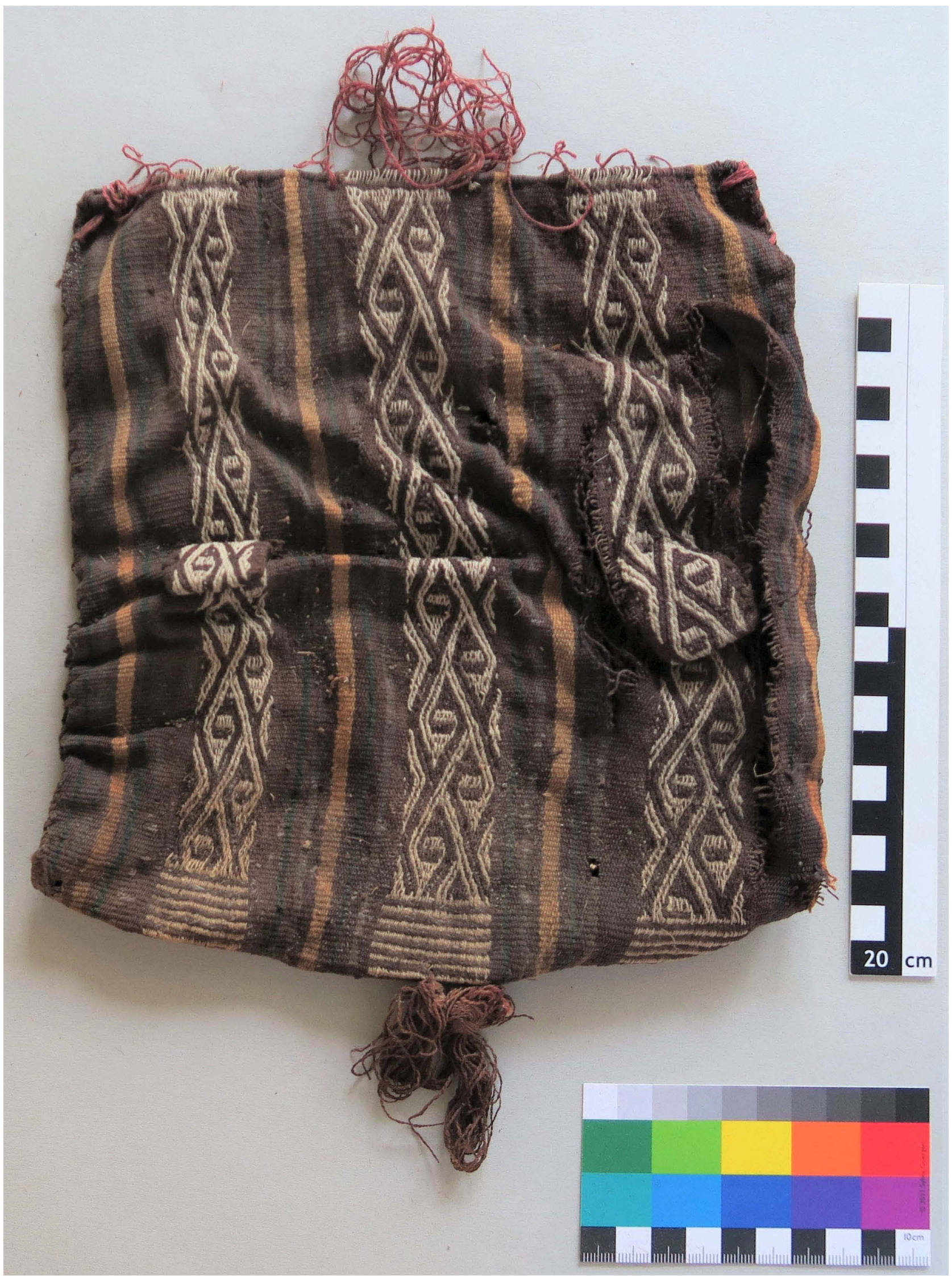

Figura 16. Vista de una de las chuspas que componen la ofrenda asociada a la momia de Marburg (Fotografía Isabel Martínez A., 2018). 


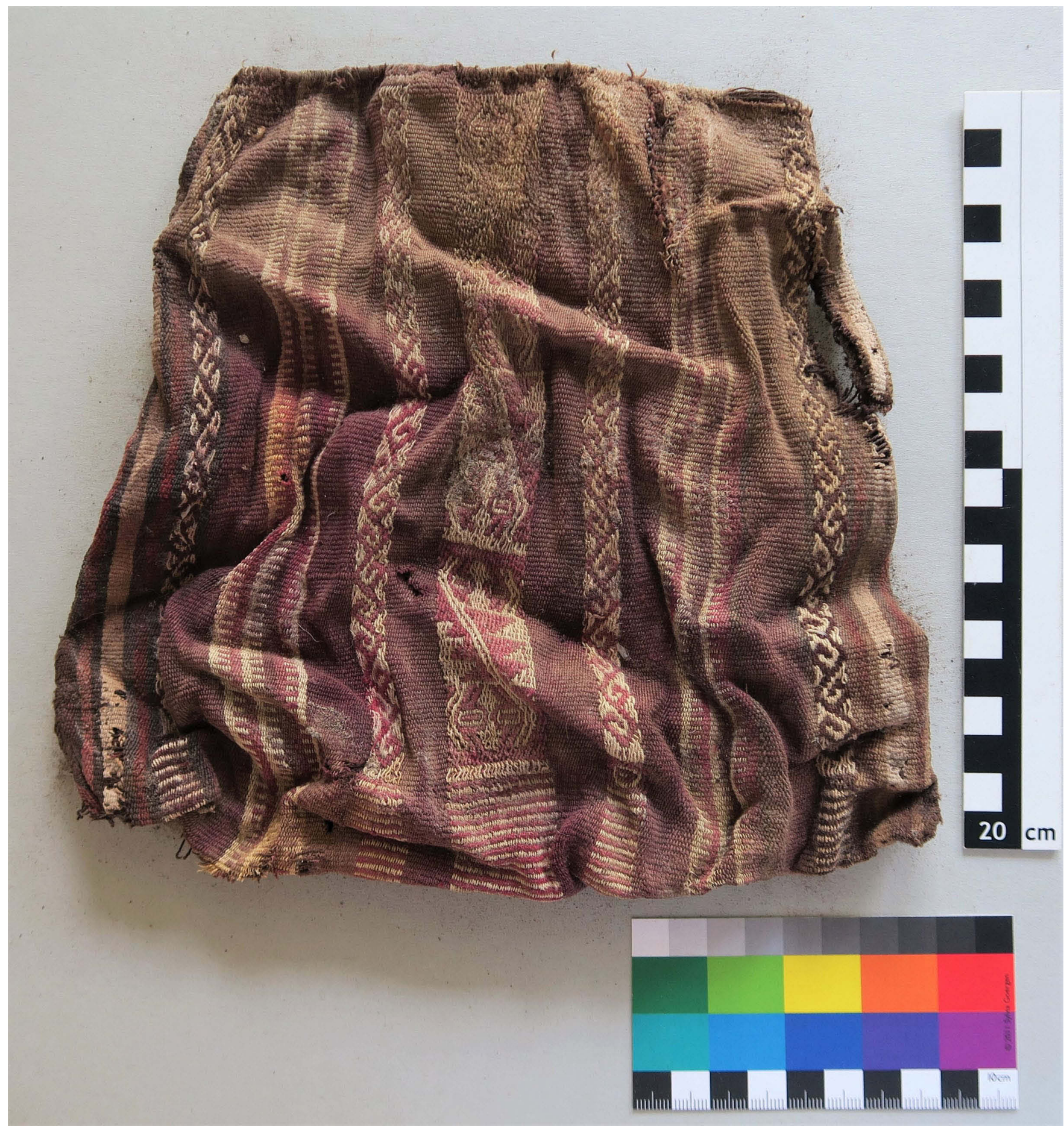

Figura 17. Vista de la segunda chuspa que forma parte de la ofrenda asociada a la momia de Marburg (Fotografía Isabel Martínez A., 2018).

mediante una línea diagonal flanqueada por líneas aserradas. La zona inferior de la franja termina en un peinecillo o k’utu largo y ancho, que da el efecto de líneas en crema y granate alternadas.

El ícono figurativo apenas descrito encuentra su correspondencia en la clasificación de Horta (2005:58 y 68, Figura
106), catalogado como una serpiente bicéfala de cuerpo diagonal.

Las franjas con íconos no-figurativos corresponden a cuatro que presentan el mismo diseño, dos de las cuales, que se hallan a ambos lados de la franja central separadas por la pampa de color granate, están formadas por hilos de 


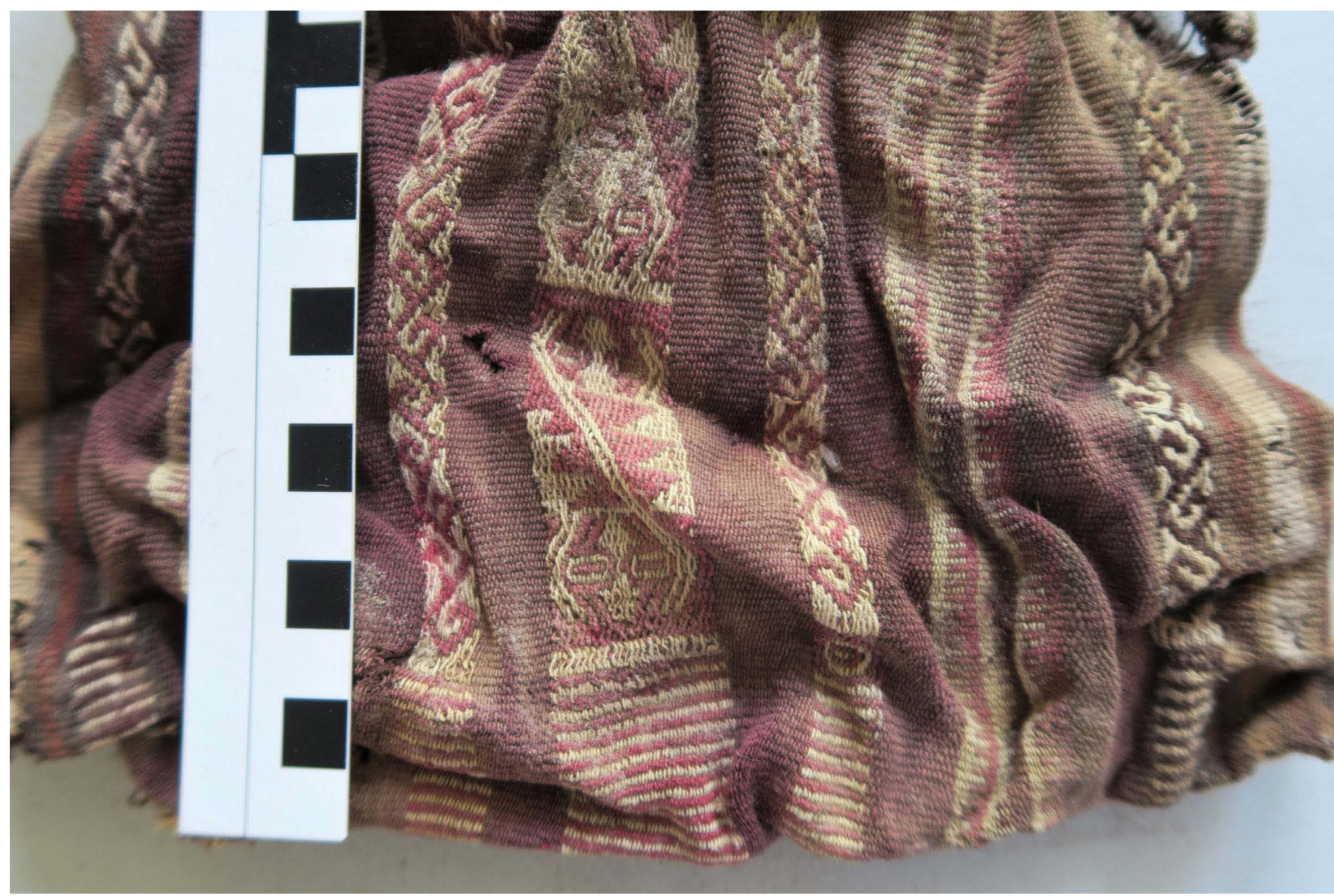

Figura 18. Detalle de la franja central con el motivo de la serpiente bicéfala de cuerpo diagonal (Fotografía Isabel Martínez A., 2018).

urdimbre de color rojo y crema, mientras que las otras dos, ubicadas cerca de los bordes laterales, fueron realizadas con hilos de urdimbre de color morado oscuro y crema. La zona inferior de la franja termina en un peinecillo largo y ancho, que da el efecto de líneas alternadas de color crema y granate, crema y morado oscuro. El ícono no-figurativo apenas descrito encuentra su correspondencia en la clasificación de Horta (2005:93 y 108, Figura 314) y corresponde a volutas en "S" que conforma una larga secuencia similar a guirnaldas con las cabezas entrelazadas.

Las dos franjas con peinecillo se posicionan entre las cuatro franjas con íconos no-figurativos, separados por la pampa de color granate y tienen, cada una, la siguiente composición de listas: crema/peinecillo en rojo y crema/rojo/ crema/peinecillo en granate y crema/granate/rojo/peinecillo rojo y crema/ rojo.

Finalmente, ambos bordes laterales del cuerpo de la chuspa terminan con ocho listas monocromas de diversos colores, presentando una división en tres partes: una lista central más ancha de color crema flanqueada por listas de menor e igual ancho. La secuencia de colores es la siguiente: rojo/morado oscuro/rojo/morado oscuro/crema/morado oscuro/rojo/morado oscuro.

La primera inkuña (Figura 19) presenta una decoración textil se da en listas verticales, de diferentes anchos, de color café sobre una pampa de color crema, con un total de diecinueve, de las cuales tres con peinecillo. La técnica textil corresponde a la faz de urdimbre para las zonas llanas sin decoración y listas monocromas, así como peinecillo.

Se evidencian los cuatro bordes, superior, inferior y laterales, y las cuatro terminaciones en las esquinas. Los bordes laterales son terminaciones simples de trama, mientras que los bordes superior e inferior están realizados con la técnica de trama en torzal, en crema y café oscuro, que forman en una fila central unas especies de rombo en crema unidos por líneas en café oscuro, y una primera y última pasadas de trama con un hilo más grueso. Las cuatro esquinas, prolongaciones de la trama de estos bordes en las orillas de urdimbre, fueron realizados con la técnica de cordón trenzado de dos colores con el motivo de zig-zag.

De acuerdo a lo que se observa en relación a la leve deformación que presenta en la zona central, por la dirección de 


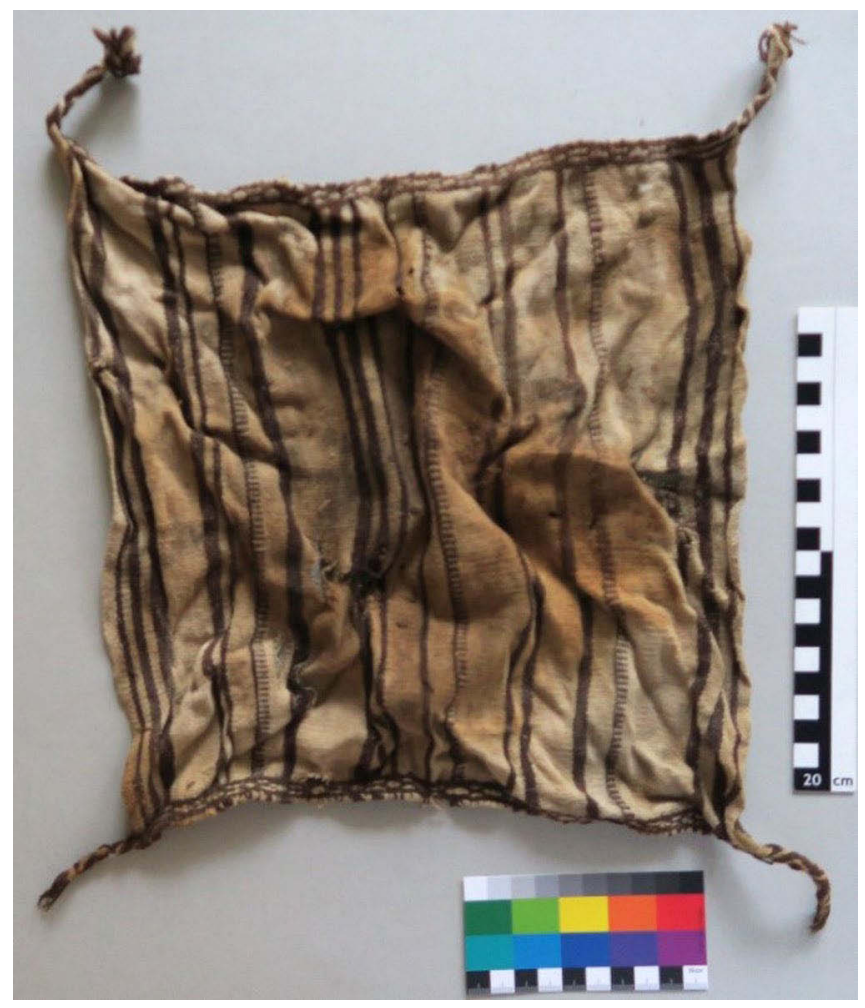

Figura 19. Vista de una de las inkuñas que componen la ofrenda asociada a la momia de Marburg (Fotografía Isabel Martínez A., 2018).

los pliegues y la mancha café, se puede conjeturar que esta pieza habría envuelto un contenido, tal como corresponde a su función, anteriormente citada. Pudo haber sido depositada en forma de bulto, probablemente conteniendo hojas de coca, pero no es posible determinar si el contenido se perdió con el traslado de la momia desde Arica a Marburg o a su posterior llegada al destino final.

La segunda inkuña (Figura 2o) presenta una decoración que se da en cuatro módulos, o bloques según la terminología usada por Horta y Agüero (2009:186), de listas verticales, de diferentes anchos y composición, separados por la pampa en color café claro, con una pampa central de color crema. Presenta dos módulos centrales, a ambos costados de la pampa de color crema, donde uno de ellos se compone de listas monocromas de diferentes colores y anchos, mientras que el otro está compuesto además por una serie de listas con peinecillo; y dos módulos laterales, siendo uno más ancho que el otro y lo forman listas monocromas, con peinecillo y una franja ancha con ajedrezado con líneas diagonales. La técnica textil con la cual fue confeccionada corresponde a la faz de urdimbre para las zonas llanas sin decoración y listas monocromas, y peinecillo para las listas con ese diseño y para el ajedrezado.

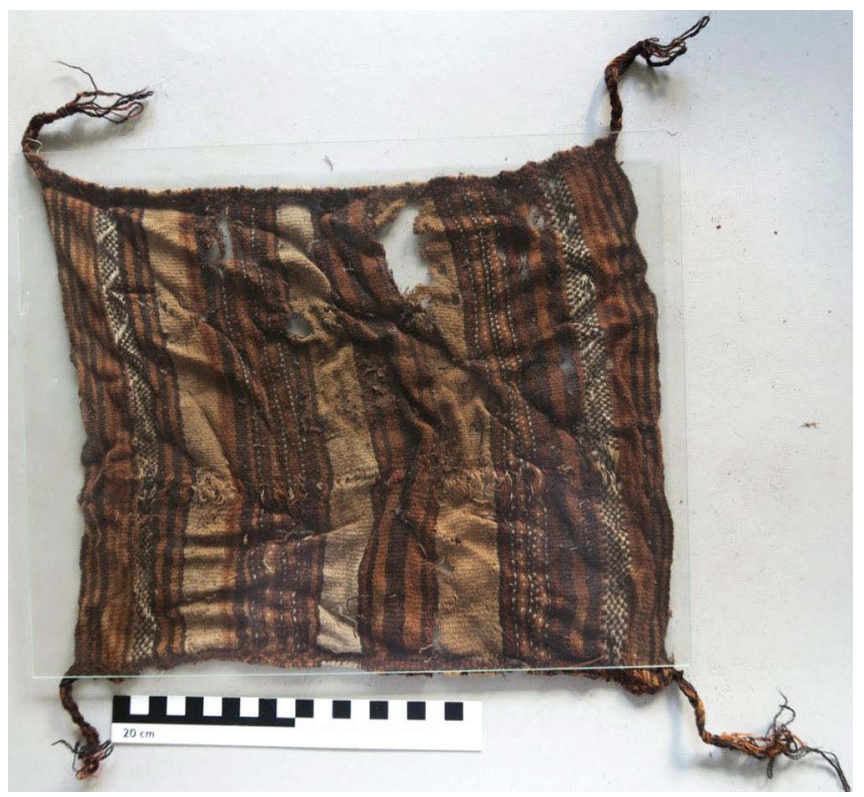

Figura 2o. Vista de la segunda inkuña asociada a la ofrenda de la momia de Marburg (Fotografía Isabel Martínez A., 2018).

Los bordes laterales son terminaciones simples de trama, mientras que los bordes superior e inferior estarían realizados con la técnica de trama en torzal en color café oscuro y café claro, que forman en una fila central unos rombos en color café vicuña unidos entre sí, con una primera pasada de trama con un hilo más grueso. Las cuatro esquinas, prolongaciones de la trama de estos bordes en las orillas de urdimbre, fueron realizadas con la técnica de trenzado simple de tres cabos.

De acuerdo a lo que se observa en relación a la leve deformación que presenta, por la dirección de los pliegues y abultamiento en la zona central, también se puede conjeturar que esta pieza habría envuelto un contenido y que pudo haber sido depositada en forma de bulto, probablemente conteniendo hojas de coca, pero que con el traslado de la momia desde Arica a Marburg o posterior a su llegada a destino final, se habría abierto, perdiéndose su contenido original.

\section{Recontextualización de la Momia}

En base al análisis realizado podemos circunscribir a este individuo, como ya se ha planteado en la introducción, al período Intermedio tardío (ca. 1000-1470 d.C.) de la zona de Arica, norte grande de Chile y, con más exactitud, como perteneciente a la cultura Arica. Muchos son los elementos que nos llevan a tal adscripción, como la forma y función de los textiles del ajuar y de la ofrenda, la materialidad y técnicas 
empleadas en su confección, pero sobre todo por la gama de colores empleada, la composición espacial y la iconografía de los mismos.

Dentro de la forma y función de los textiles, tanto del ajuar como de la ofrenda, tenemos la presencia de los más representativos y frecuentes tipos de la indumentaria de la cultura Arica, según lo señalado por Carolina Agüero (2000) y Helena Horta (2005): unku, bolsa-faja, inkuña y chuspa. Asimismo, las tres últimas piezas mencionadas son los tres tipos de tejidos que presentan mayor decoración figurativa en todo el desarrollo de la zona de Arica.

Por la técnica de confección del posible unku, cuyos restos e improntas en la piel se hallan distribuidos en toda la zona de la espalda y hombros del individuo, podemos plantear una prenda de estilo no-local, ya que en esa zona las túnicas eran realizadas con la técnica de faz de urdimbre, como los restos del segundo unku que presenta listas en el sentido vertical de color crema sobre fondo café oscuro, al menos hacia los costados, que se evidencia en la rodilla derecha y sobre ambas manos y que pudo cubrir todo el cuerpo, sobre las otras prendas.

Por otro lado, debido a la escasa bibliografía encontrada en relación a la bolsa-faja, no fue posible atribuirla a una determinada fase durante el período Intermedio tardío en la zona de Arica. En la colección Nielsen del Museo Regional de Iquique, norte de Chile, se encuentra un ejemplar de similares características en cuanto a la disposición espacial, aunque esta pieza varía en relación al patrón cromático donde predominan los colores teñidos (Méndez 2015:19, Bolsa-faja, $\mathrm{S} / \mathrm{P}, 1465)$ y no se hace referencia a un posible contexto ni fechado. Retomando a Horta, la bolsa-faja:

"es una prenda textil de uso restringido a través de todo el Intermedio Tardío: su recurrencia es mucho menor que la de los otros dos textiles decorados por excelencia, como son la chuspa y la inkuña. Todo indica que la bolsa-faja fue símbolo del elevado prestigio social de algunos miembros de la comunidad: su ausencia en la gran mayoría de las tumbas confirma lo manifestado, frente a un número muy menor de ajuares que presentan simultáneamente dos bolsa-fajas ricamente decoradas" (Horta 2015:193)

La bolsa-faja habría sido usada exclusivamente para guardar y trasladar las hojas de coca, vinculada a su consumo y circulación entre los miembros de la élite.

En cuanto a la inkuña, reutilizada como posible taparrabo, por las características observadas en la composición espacial es posible insertar esta pieza en la clasificación de Horta y Agüero (2009:203, Figura 16) como el grupo 2D, es decir, correspondería a una inkuña estilo San Miguel-Pocoma (Horta y Agüero 2009:217), que presentan rasgo de filiación estilística tanto de San Miguel como de Pocoma, con la innovación en las pampas listadas, lo que las autoras han denominado listado Pocoma, que corresponde al patrón cromático de la presente pieza.

Uno de los íconos más representativos es la figura antropomorfa bicéfala, siendo la que presenta mayores dimensiones y que se ubicaría en la franja central más ancha. Según lo expresado por Horta (2005:125), la influencia Pocoma sobre San Miguel se inicia alrededor del 1200 d.C., notándose tanto en la cerámica como en los textiles, con la introducción de nuevos íconos, entre los cuales figuran los primeros antropomorfos bicéfalos. Esta figura antropomorfa bicéfala que se encuentra también en algunos textiles de San Miguel tardío, pero sin su carácter rectilíneo, fue típica de las representaciones antropomorfas de los textiles de filiación Chiribaya (Horta 1997:94).

Además, en el caso de las dieciséis figuras antropomorfas bicéfalas registradas por Horta, seis de ellas presentan la coincidencia de "tocado erguido", conjunto de cuatro hexágonos concéntricos en el cuerpo y “orejeras” (2005:31), como es observado en la figura de esta pieza. Asimismo, entre los motivos decorativos más frecuentes de las inkuñas del grupo 2D se encuentran las figuras antropomorfas erguidas, el camélido de cuatro patas, el felino, los ganchos y la franja diagonal aserrada, que encontramos también en la pieza bajo análisis.

En relación a la procedencia de las piezas pertenecientes al grupo 2D analizadas por dichas investigadoras, tenemos que la mayoría, en total seis, proviene del cementerio Playa Miller-3 (PLM-3), una de Playa Miller-4 (PLM-4), ubicados en la costa al Sur de la ciudad de Arica, y una de Azapa-140 en el valle de Azapa. El sitio de PLM-3 es un cementerio de una población compuesta por pescadores, cazadores de lobos marinos y mariscadores que vivió en la costa de Arica hacia la segunda mitad del Intermedio tardío, lo que se evidencia por la presencia masiva de implementos de pesca, arponeo y extracción de mariscos en todos los ajuares funerarios (Focacci 1997; Horta 2000). Es a fines de ese periodo (ca. 1250-1450 d.C.) que surgen en esa zona la balsa, el capacho y el porta-arpón y "es entre las ofrendas costeras, que observamos una acentuada presencia de textiles de estilos foráneos (Chiribaya, 'Tarapaqueño', así como otros aún no definidos), mezclados con los locales (San Miguel, Pocoma y Gentilar)" (Horta 2000:240). Los fechados por termoluminiscencia de las cerámicas asociadas a este grupo de inkuñas varía entre $960 \pm 80,1.215 \pm 8$ o d.C. y $1.355 \pm 55$ d.C. (Horta y Agüero 2009:206; Uribe 1999).

La Cultura Arica se desarrolló en la zona geográfica de los valles interiores y franja costera del extremo norte grande 
de Chile, sub-área de los Valles Occidentales del área mayor centro-sur andina (Horta 2005:13). Esta área geográfica está sujeta a una gran aridez, por lo que la presencia de valles interfluviales como Lluta, Azapa, Vítor y Camarones permitieron, por sus condiciones favorables, el asentamiento humano (Horta 2015:31).

Esta cultura tuvo dos fases de desarrollo: San Miguel y Gentilar, con un periodo de transición denominado Pocoma (Horta 2005:12). Se caracterizaban por tener una economía mixta de subsistencia ya que eran agricultores, pastores y pescadores, existiendo un sistema recíproco de complementariedad ecológica para el Intermedio tardío en esa zona (Horta 2005:14; 2015:21-22). El panorama general del Intermedio tardío fue de multietnicidad en lo que respecta a la tradición de Valles Occidentales, representada por los grupos Maytas, San Miguel, Pocoma y Gentilar, y con presencia de otros grupos culturales, como por ejemplo provenientes del altiplano y del extremo sur del actual Perú (Horta 2015:24). Las poblaciones de la tradición de Valles Occidentales estaban organizadas en comunidades con autoridades propias, compartiendo el espacio con poblaciones altiplánicas "en el marco de relaciones simétricas" (Horta 2015:27; Santoro et al. 1987). Asimismo, la conjunción de las diversas actividades productivas de la zona llevó a "un estado de relativo bienestar general, que se tradujo en un incremento de los bienes poseídos individualmente por cada miembro de la comunidad" (Horta 2005:14), lo que se vería reflejado en la cantidad y calidad de los objetos que formaban parte del ajuar y ofrendas funerarios que acompañaban a cada individuo.

El patrón de enterramiento es la fosa cilíndrica o ampollar, sin ningún revestimiento de piedra, donde el cuerpo del individuo era enterrado en una posición fuertemente flexionada, envuelto en una o más túnicas y amarrado con cuerdas trenzadas de fibra vegetal o de camélido (Horta 2015:351), acompañado por un ajuar y ofrendas. El ajuar correspondía a la vestimenta de uso cotidiano -por la presencia de variados remiendos- aunque en algunos casos se hallaron también piezas textiles sin uso, lo que lleva a Helena Horta a inferir, por lo que concierne a la cultura Arica, que ciertos "miembros de la comunidad contaban con el privilegio de poseer prendas de uso no-cotidiano, o confeccionadas especialmente para el rito de la muerte" (2005:15).

En relación al estatus de los individuos del Intermedio tardío, reflejado en los diversos contextos funerarios, el prestigio del difunto "está directamente relacionado con el rol que cumple en el sistema socio-político en el cual se halla inmerso" (Horta 2015:176), tomando en consideración los bienes funerarios asociados al cuerpo, los cuales están relacionados con la actividad económica que habría ejercido en vida. Para el Intermedio tardío se registra un aumento en la calidad y en la cantidad de bienes funerarios, así como el carácter simbólico de los objetos, en relación al periodo anterior, período Medio, lo que podría ser interpretado como un "signos de una temprana diferenciación social" (Horta 2015:176).

Es en este periodo que se evidencia un incremento de ciertos tipos de textiles en la ofrenda mortuoria, como la bolsa-faja y la inkuña, cuya función era la de contener hojas de coca. Existe una diferencia en la cantidad de inkuñas por cementerio entre el valle y la costa, siendo mayor en esta última zona; la excepción de los cementerios de valle es Azapa 8 que se comporta en muchos aspectos como un cementerio de la costa. En los cementerios de los valles, la inkuña "funciona como un bien al cual los miembros de la comunidad tenían un acceso más o menos igualitario" (Horta 2015:184), registrándose generalmente una de estas piezas por tumba. En los cementerios de la costa, la diferencia en la frecuencia radica en la concentración de este ítem asociado a ciertos individuos, ya que al igual que en los cementerios del valle el estándar es de uno a dos por tumba. Esta diferencia en la frecuencia entre costa y valle es interpretada por Helena Horta como el reflejo del auge económico de la cultura Arica gracias a la explotación de los diversos recursos marinos "que en forma de excedente se intercambiaban con poblaciones vecinas y distantes en una compleja red de tráfico interregional" (Horta 2015:189), lo que habría llevado a un incremento del poder y prestigio de los jefes étnicos de la costa y donde las hojas de coca habrían jugado un rol fundamental en las ceremonias de reciprocidad.

La bolsa-faja, contenedora por excelencia de hojas de coca, hace su aparición a partir de la segunda mitad del Intermedio tardío (ca. 1200-1470 d.C.), a diferencia de la chuspa y de la inkuña que ya se registran en los inicios de este periodo. Sin embargo, son la inkuña y la bolsa-faja innovaciones representativas del Intermedio tardío en la zona de Arica, ya que su presencia no se evidencia ni antes ni después de ese periodo (Horta 2015:187) y como ya mencionamos su uso fue restringido ya que su recurrencia es mucho menor que los otros dos tipos textiles.

\section{Conclusiones}

Los resultados de este análisis nos ratifican, a grandes rasgos, su adscripción cultural y espacial al periodo Intermedio tardío de la zona de Arica, y más específicamente podríamos estar hablando, en primera instancia, sea por la composición espacial de la inkuña como por la presencia de la bolsa-faja, de un contexto funerario de filiación San Miguel-Pocoma con presencia de posibles bienes de intercambio, de filiación Maytas-Chiribaya, que forman parte de la 
ofrenda, con un fechado acotado aproximadamente entre 1200 y 1300 d.C., datación relativa que deberá ser posteriormente cotejada por los resultados del fechado de radiocarbono, así como por el análisis de los objetos no textiles.

Los componentes del ajuar, así como de las ofrendas, nos están indicando que el individuo habría tenido cierto poder y prestigio dentro de su comunidad. Esta aseveración se apoya, tanto en la presencia de la bolsa-faja, como por la rica iconografía presente en la inkuña-taparrabo. Estas piezas, como ya vimos, tenían como función la de contener hojas de coca, bien importante en las comunidades andinas precolombinas en los intercambios de reciprocidad, rituales y como ofrenda. Los íconos plasmados en la inkuña-taparrabo nos remiten a personajes con características específicas, como el uso de orejeras y tocado, símbolos de prestigio y status en todos los Andes y a seres zoomorfos que representan el poder y la fuerza naturales, tales como el felino. Asimismo, el intrincado peinado y posibles restos de metal en la mayor parte de la cara de la momia, nos podrían estar indicando que habría sido sepultado con una máscara funeraria, otro elemento de escasa recurrencia y vinculada a personajes de alto rango. Este individuo fue inhumado con un total de tres inkuñas (una en el ajuar y dos en la ofrenda), lo que nos lleva a proponer, debido a la concentración de este bien mencionado anteriormente, así como la presencia de objetos relativos a la ergología marítima en las ofrendas, que su entierro primario habría estado ubicado en alguno de los cementerios de la costa de Arica. Posteriores análisis nos permitirán acotar aún más esta circunscripción geográfica.

\section{Agradecimientos}

Agradecemos a Nina Ullrich, curadora del Museum Anatomicum de la Philipps Universität, Marburg, Alemania, por la confianza y por permitirnos analizar los textiles asociados a la momia que tienen en custodia.

\section{Referencias Citadas}

Agüero, Carolina

2000 Las tradiciones de Tierras Altas y de Valles Occidentales en la textilería arqueológica del Valle de Azapa. Chungara 32(2): 217-225.

Arriaza, Bernardo, Marvin J. Allison, Vivian Standen, Guillermo Focacci y Juan Chacama

1986 Peinados precolombinos en momias de Arica. Chungara 16-17: 353-375.
Focacci, Guillermo

1997 Evidencias culturales andinas en registros arqueológicos Playa Miller-3. Diálogo Andino 16: 101-122.

Horta, Helena

1997 Estudio iconográfico de textiles arqueológicos del valle de Azapa, Arica. Chungara 29 (1): 81-108.

2000 Diademas de plumas en entierros de la costa del Norte de Chile: ¿Evidencias de la vestimenta de una posible parcialidad pescadora?. Chungara 32(2): 235-243.

2005 Arte textil prehispánico. Diseños de los tejidos de la cultura Arica, norte de Chile (10oo-1470 d.C.). Serie Colección Estudios Regionales y Locales de la Universidad Bolivariana, Sede Santiago, Imprenta LOM.

2015 El señorío Arica y los Reinos Altiplánicos: complementariedad ecológica y multietnicidad durante los siglos pre-conquista en el Norte de Chile (100o-1540 d.C.). Ocho Libros Editores, Santiago de Chile.

Horta, Helena y Carolina Agüero

2009 Estilo, iconografía y diseño de las inkuñas prehispánicas del Norte de Chile durante el Periodo Intermedio Tardío (1.00o-1.40o d.C.). Chungara 41(2):183-227.

Méndez, Pablo

2015 Prácticas funerarias en las costas de Tarapacá. Colección Nielsen. Museo Regional de Iquique.

Minkes, Wynne

2008 Warp the Loom-Warp the Dead. Trapezoid shaped textiles from the Chiribaya Culture, South Peru, AD 900-1375. http://digitalcommons.unl.edu/tsaconf/116 (26/01/2018).

Phipps, Elena

2008 Woven to Shape: a Pre-Columbian Trapezoidal Tunic from the South Central Andes in the Metropolitan Museum of Art. http://digitalcommons.unl.edu/ tsaconf/233 (26/o1/2018).

Rosenzweig, Alfredo y Bat-ami Artzi

2011 A Chiribaya Textile Woven with Human Hair. Boletin del Museo Chileno de Arte Precolombino 16(1): 93-104.

Santoro, Calogero, Jorge Hidalgo y Alfonso Osorio

1987 El estado Inka y los grupos étnicos en el sistema de riego de Socoroma. Chungara 19: 71-92.

Uribe, Mauricio

1999 La cerámica de Arica 40 años después de Dauelsberg. Chungara 31(2): 189-228. 